\title{
STABILITY INDICATING HPLC METHOD FOR THE DETERMINATION OF AGOMELATINE INPLASMA AND TABLET FORMULATION
}

\author{
Hamed Hamed Mohammed Abuseada \\ Analytical Chemistry Department, Faculty of Pharmacy, Al-Azhar University, Cairo, Egypt
}

\begin{abstract}
:
A stability indicating HPLC method was developed and validated for quantitative determination of agomelatine in plasma and tablet formulation in the presence of degradation products generated from forced degradation studies. An HPLC method was developed to separate the drug from the degradation products using Waters spherisorb Cyano $\mathrm{C}_{18}$ column $(250 \times 4.6 \mathrm{~mm}, 5 \mu \mathrm{m})$ and a mobile phase constituted of trifluoroacetic acid buffer and methanol $(50: 50 \% \mathrm{v} / \mathrm{v})$. The wave length of the detection is $230 \mathrm{~nm}$ at a flow rate $1 \mathrm{~mL} / \mathrm{min}$. The validation data showed that the assay is accurate, precise, sensitive, specific and reproducible for the determination of agomelatine in plasma as well as in tablet formulation in the presence of its degradants. The method is linear from $12.5-37.5 \mu \mathrm{gmL}^{-1}$ and accuracy of the method was found to be $100.5-100.9 \%$ for tablets and $97.84-101.24 \%$ for plasma. The proposed method was found to be suitable for quantitative determination and the stability study of the drug in plasma and tablet formulation.
\end{abstract}

Key words: Agomelatine, stability indicating HPLC method, plasma and tablet formulation.

\subsection{INTRODUCTION}

Agomelatine is a novel and clinically effective antidepressant drug with melatonergic $\left(\mathrm{MT}_{1} / \mathrm{MT}_{2}\right)$ agonist and $5-\mathrm{HT}_{2} \mathrm{C}$ receptor antagonist properties (Daniela, 2012). It also used in generalized anxiety disorder (Stein, et al., 2008), sleep disturbances (Srinivasan, et al., 2009), migraine and cluster headaches (http://www.ema.europa.eu/humandocs). Patients on agomelatine confirm the absence of the classic side effects of antidepressants (weight gain and sexual dysfunction) and are more likely to continue treatment than they are with other drugs (Kasper, 2011). Agomelatine is not recommended for use in children and only limited clinical data is available on the use of agomelatine in elderly patients $\geq 65$ years old with major depressive episodes, therefore, caution should be exercised when prescribing it to these patients (Srinivasan, et al., 2009; Tinant, et al., 1994; Howland, 2009). Specific data on safety for the use of agomelatine in pregnancy and lactating mothers is not available (Peres, et al., 2006). Enzyme inducers like omeprazole and nicotinedecrease the serum levels of agomelatine (Peres, et al., 2006; Howland, et al., 2006). Fluoxamine and oestrogens have been found to increase the levels of agomelatine because of their enzyme inhibition (Peres, $\boldsymbol{e t}$ al., 2006). Agomelatine should not be taken in combination with the antidepressant fluvoxamine or the antibiotic ciprofloxacin, both increase the amount of agomelatine in the body, by preventing its breakdown. (Kasper, 2011). Agomelatine (N-[2-(7-methoxy-1naphthyl) ethyl] acetamide) is practically insoluble in purified water $(<0.1 \mathrm{mg} / \mathrm{mL})$ but freely soluble $(>100 \mathrm{mg} / \mathrm{mL})$ in various organic solvents such as ethanol, methanol, methylene chloride. Molecular formula of agomelatine is $\mathrm{C}_{15} \mathrm{H}_{17} \mathrm{NO}_{2}, \mathrm{MW}=243.3$ (Zlotos, 2005). Chemical structure is shown in Figure 1. 


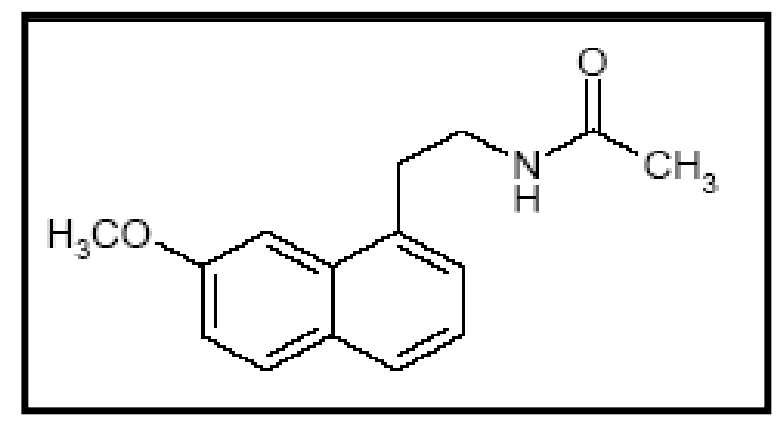

Figure 1: Chemical Structure of Agomelatine

There are several methods for determination of agomelatine in bulk drug and pharmaceutical dosage forms reported in literature (Patil, et al., 2012; Zou, et al., 2012; Wang, et al., 2012(a); Wang, et al., 2012(b ). However, stability indicating HPLC methods for the determination of the drug in presence of its degradatehave not been found.

\subsection{EXPERIMENTAL}

\subsection{Materials}

Agomelatine $99.8 \%$, from SYMED LABS LIMITED BATCH :AGM WS/11-01. Fenprofen99.11\%. Batch no 20070401 from NANTONG HAUFENG CHEMICAL CO. LTD, China. Inspago $25 \mathrm{mg}$ F.C.Tablets (Al Rowad Pharm. Ind., Egypt). All the reagents were of analytical-reagent or HPLC grade unless stated otherwise. HPLC grade water by ELGA System (Pure lab UHQ II) by further distilling and deionizing water after initiating a reversed - osmosis process, water is irradiated with short wave radiation in a UV chamber. Acetonitrile (SCHARLAU) gradient HPLC grade 3182 BATCH 13966421. Methanol (SCHARLAU) gradient HPLC grade 3322 BATCH 1392705. Formic acid 98/100\% Fisher Scientific code F/1850/PB17. Triflouroacetic acid (Fisher Scientific) code T/3256/PB05 LOT 1296530.Triethylamine AR (SD fine chem. limited).

\subsection{Instrumentation}

The HPLC system used was a Water (SCHARLAU) HPLC grade $2650 \mathrm{BATCH}$ 13791903, comprised of degasser, LC-20AT pump, SIL- 20 AC auto sampler, column compartment, SPD-20A UV. Detector.Analytical column used for this method is Waters spherisorb Cyano (250X4.6mm, $5 \mu \mathrm{m}) \mathrm{PSS} 830909$.

\subsection{Mobile Phase Preparation}

Prepare a mixture of 50\% methanol: $50 \%$ buffer solution (prepared by addition of $0.5 \mathrm{ml}$ trifluoroacetic acid to $1000 \mathrm{ml}$ water and adjust the $\mathrm{pH}$ to $2.5 \mathrm{using}$ triethylamine).

\subsection{Standard Preparation}

Standard stock solution was prepared by dissolving $25 \mathrm{mg}$ of agomelatine in sufficient amount of methanol in a $100 \mathrm{~mL}$ volumetric flask and diluted up to the mark with methanol, sonnicate for 5 minutes, dilute $10 \mathrm{ml}$ of this solution into $100 \mathrm{ml}$ using the same solvent.

\subsection{Sample Preparation}

10 tablets were grinded and a quantity containing $25 \mathrm{mg}$ agomelatine was transferred into a $100 \mathrm{~mL}$ volumetric flask, $70 \mathrm{ml}$ of methanol is added. Sonnicate for 20 minutes, 
complete to volume with methanol, mix, and pass through a suitable membrane filter $0.45-\mu \mathrm{m}$ porosity. $10 \mathrm{ml}$ of this solution is diluted into $100 \mathrm{ml}$ using the same solvent.

\subsection{Chromatographic Conditions}

Before the mobile phase was delivered into the system, buffer solution and methanol were filtered through $0.45 \mathrm{~mm}$, PVDF membrane filter and degassed using vacuum. The chromatographic conditions used for the analysis were given below.

Column : Waters spherisorbCyano $\mathrm{C}_{18}(250 \mathrm{X} 4.6 \mathrm{~mm}, 5 \mu \mathrm{m})$ column.

Wavelength : $230 \mathrm{~nm}$

Injection volume : $20 \mu 1$

Flow rate : $1.0 \mathrm{~mL} \mathrm{~min}^{-1}$

Column temperature: $30^{\circ} \mathrm{C}$

Run time : 8 min

\subsection{Procedures}

\subsubsection{Study of The Experimental Parameters}

Different experimental conditions including type of column, mobile phase composition, detection wavelength, flow rate, and nature of internal standard were extensively studied in order to determine the optimal conditions for the assay procedure. Variables were optimized by changing each in turn, while, keeping all others constant. Chromatographic parameters are calculated according to the USP (The United States Pharmacopoeia 30, 2007) and BP (The British Pharmacopoeia 2007) guidelines.

\subsubsection{Construction of Calibration Graph}

Aliquots of the suitable agomelatine standard solutions were transferred into a series of $10-\mathrm{mL}$ volumetric flasks so that the final concentration was in the range of 12.5$37.5 \mu \mathrm{g} / \mathrm{mL}$. Then the flasks were completed to volume with the mobile phase. $20 \mu \mathrm{L}$ aliquots were injected (triplicate) and eluted with the mobile phase under the optimum chromatographic conditions. A plot of the average peak area versus the final concentration in $\mu \mathrm{g} / \mathrm{mL}$ was then constructed to obtain the standard calibration graph. Alternatively, the linear regression equation was derived.

\subsubsection{Procedure For Acid Degradation}

$50.0 \mathrm{~mL}$ of $2 \mathrm{~N} \mathrm{HCl}$ was added to $25 \mathrm{mg}$ of agomelatine and reflux for about 5 hours, the solution was allowed to attain room temperature, then neutralized with $2 \mathrm{~N} \mathrm{NaOH}$. Evaporate under vacuum to dryness. The residue was extracted three times with $30 \mathrm{ml}$ methanol and filtered into $100 \mathrm{~mL}$ volumetric flask then the volume was completed to the mark with methanol.

\subsubsection{Application Of The Proposed Method to The Analysis of Agomelatine in Inspago 25mg Tablets \\ Different volumes of solution prepared from tablets containing different concentrations of agomelatine were analyzed as described under Construction of the calibration graph. The concentration of the drug was determined using, either the calibration curve or the corresponding regression equation. The results obtained were compared to those given with the reference method (Patil, et al., 2012).}

\subsubsection{Application of the proposed method to the analysis of agomelatine in plasma}

$1 \mathrm{ml}$ of a solution containing different concentrations of agomelatine $(25-55 \mu \mathrm{g} / \mathrm{mL})$ and the same concentration of internal standard $(20 \mu \mathrm{g} / \mathrm{mL})$ in acetonitrile was mixed with $0.5 \mathrm{ml}$ plasma, vortex for $1 \mathrm{~min}$. and centrifuged at $5000 \mathrm{rpm}$ for $10 \mathrm{~min}$. and $20 \mu \mathrm{l}$ of the clear 
acetonitrile supernatant was removed and injected directly into the HPLC system as described under Construction of the calibration graph. The concentration of the drug was determined using, either the calibration curve or the corresponding regression equation. The results obtained were compared to those given with the reference method (Patil, et al., 2012).

\subsection{RESULTS AND DISCUSSION}

\subsection{Optimization of the chromatographic conditions}

The primary target in developing this stability indicating HPLC method was to achieve good resolution between agomelatine and its degradants. To achieve the separation of degradation products, stationary phase of spherisorb column and a combination of mobile phase were used. The separation of degradation products and agomelatine was achieved on spherisorbcyano $(250 \mathrm{X} 4.6 \mathrm{~mm}, 5 \mu \mathrm{m})$ column and buffer: methanol $(50: 50 \% / \mathrm{v} / \mathrm{v})$ as a mobile phase. Mobile phase flow rate was maintained at $1.0 \mathrm{~mL} \mathrm{~min}^{-1}$ and eluent were monitored at $230 \mathrm{~nm}$. A $20 \mu \mathrm{l}$ of sample was injected using a fixed loop and the total run time was $8 \mathrm{~min}$.

\subsection{STABILITY INDICATION OF THE METHOD}

Agomelatine was reported to be susceptible to acidic and alkaline conditions, but slight degradation was observed in oxidative and thermal conditions. The molecule was found to be stable under water hydrolytic and photolytic conditions. The stability-indicating capability of the proposed method was tested after accelerated acid degradation of agomelatine. Degradation products did not interfere with the intact drug peak either in standard solution (figures $2 a, b, c)$ or in plasma (figures3a,b). These results demonstrated the ability of the proposed method to be used as a stability-indicating HPLC method for the analysis of agomelatine in plasma as well as tablet formulation.

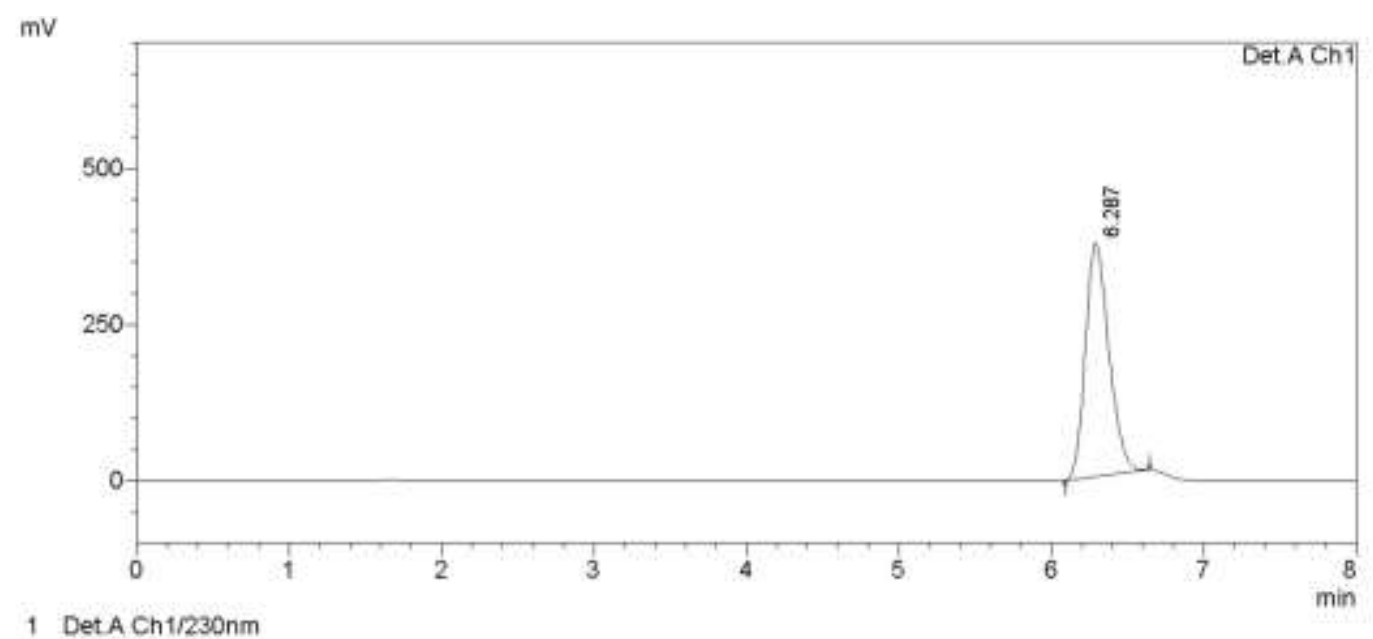

Figure 2a: HPLC Chromatogram of intact Agomelatine $(45 \mu \mathrm{g} / \mathrm{mL})$ 


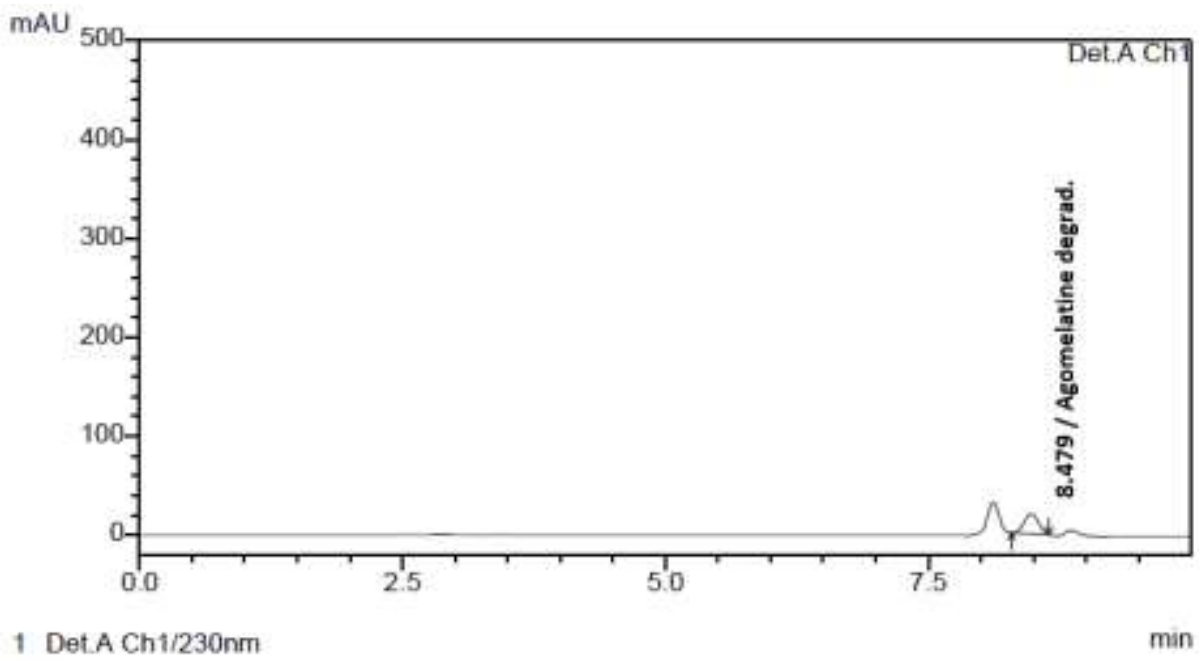

Figure 2b: HPLC Chromatogram of Agomelatine degradate $(100 \mu \mathrm{g} / \mathrm{mL})$

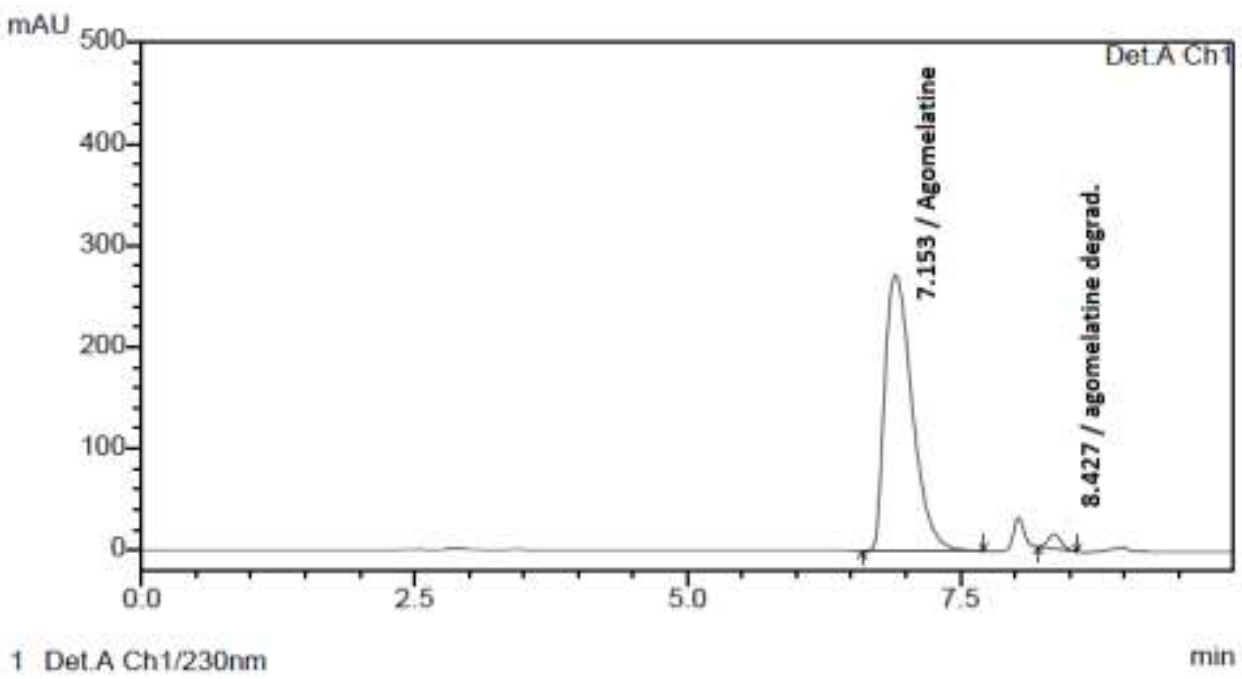

Figure 2c: HPLC Chromatogram of intact Agomelatine $(45 \mu \mathrm{g} / \mathrm{mL})$ and Agomelatine degradate $(100 \mu \mathrm{g} / \mathrm{mL})$

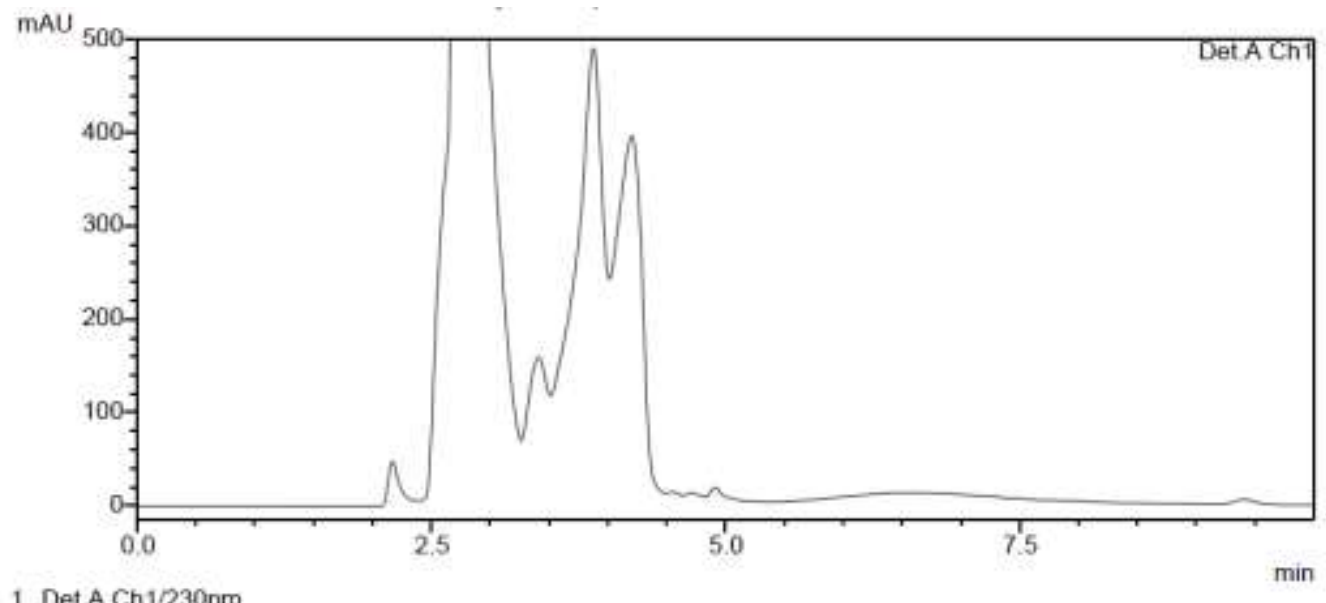

1 Det.A Ch1/230nm

Figure 3a: HPLC Chromatogram of Plasma Blank 


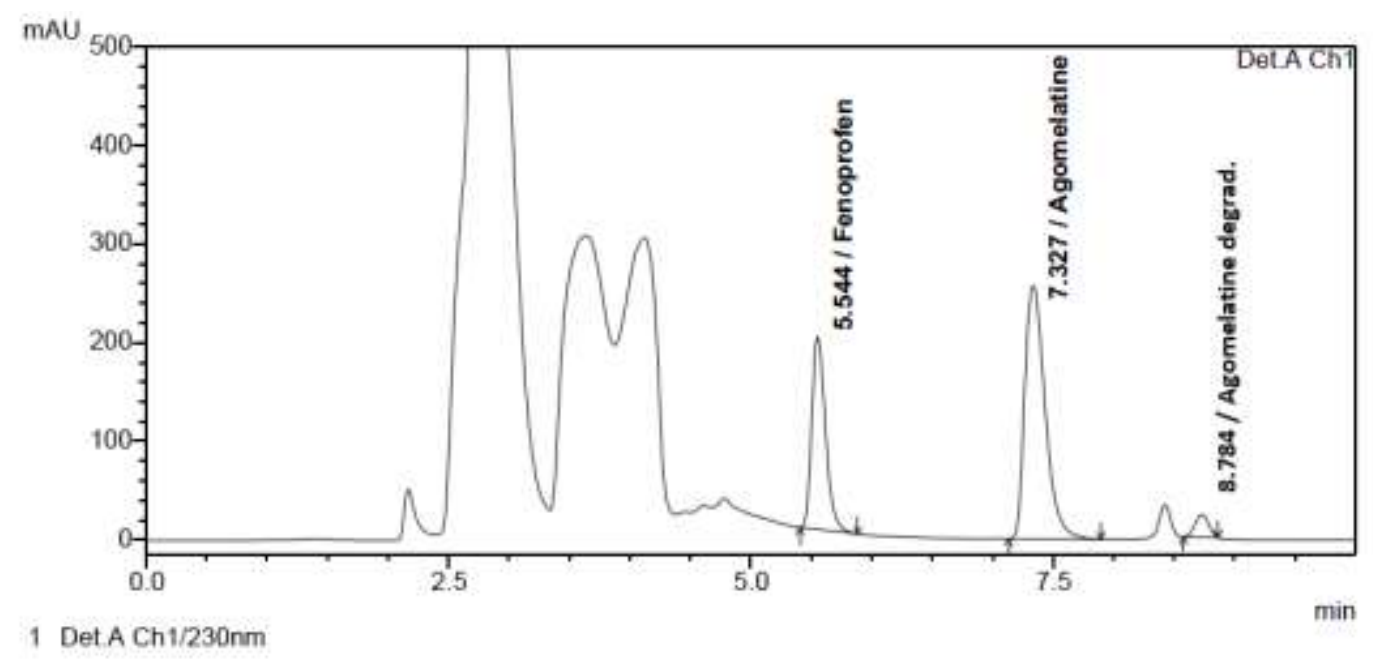

Figure 3b: HPLC Chromatogram of Agomelatine $(45 \mu \mathrm{g} / \mathrm{mL})$,Fenoprofen (IS)(20 $\mu \mathrm{g} / \mathrm{mL})$ and Agomelatine degradate $(100 \mu \mathrm{g} / \mathrm{mL})$ in Plasma

\subsection{METHOD VALIDATION}

The optimized chromatographic conditions were validated by evaluating linearity,accuracy,precision, limit of detection, limit of quantification,robustness,specificity, and selectivity in accordance with ICH guidelines (ICH, 2003, 2005). The validation parameters are showen in Table 1.

\begin{tabular}{|c|c|}
\hline \multicolumn{2}{|c|}{ Table 1: Validation Parameter of Agomelatine by HPLC } \\
method
\end{tabular}




\subsubsection{LINEARITY}

The curve proved to be linear over a concentration range of $12.5-37.5 \mu \mathrm{g} \mathrm{mL}^{-1}$ (Figure 4).Standard solutions were prepared at five concentrations $(12.5,17.5,25,30$ and $37.5 \mu \mathrm{g} \mathrm{mL}$ $\left.{ }^{1}\right)$ were injected in triplicate. Linear regression of concentrationVs peak area resulted in an average coefficient of determination $\left(R^{2}\right) 0.999$. Regression equation is $Y=172431.477 x+$ 56679.018(Figure $\varepsilon$ ). The method was found to be linear as the $\mathrm{R}^{2}$ is greater than 0.99 .

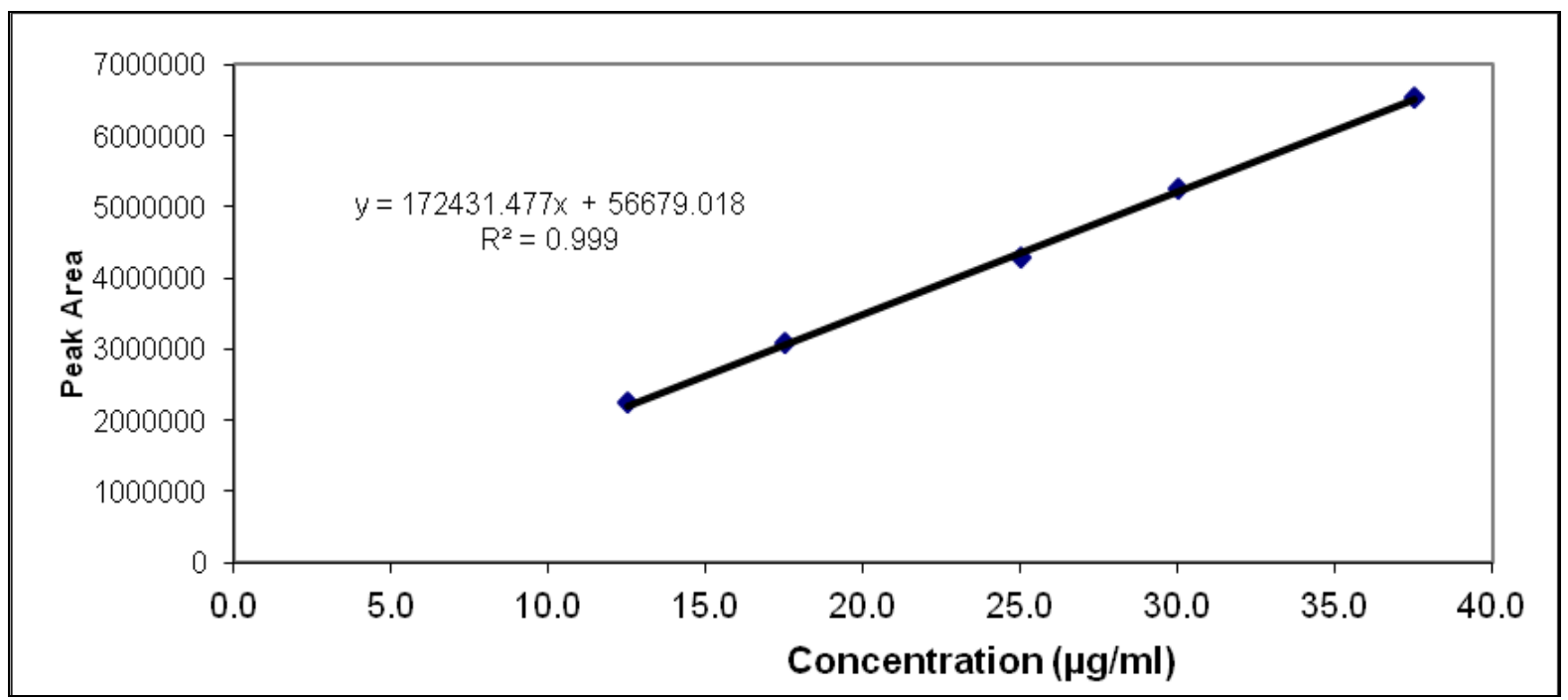

Figure 4: Linearity Curve of Agomelatine

In plasma, solutions were prepared at six concentrations of agomelatine $(25,30,35,45,50$ and $55 \mu \mathrm{g} \mathrm{mL}^{-1}$ ) and $20 \mu \mathrm{g} \mathrm{mL}^{-1}$ of IS were extracted from plasma and injected in triplicate. Linear regression of concentration Vs peak area ratio resulted in an average coefficient of determination $\left(\mathrm{R}^{2}\right)$ 0.999. Regression equation is $\mathrm{Y}=0.037 \mathrm{x}+0.069$ (Figure ${ }^{0}$ ). The method was found to be linear as the $\mathrm{R}^{2}$ is greater than 0.99 .

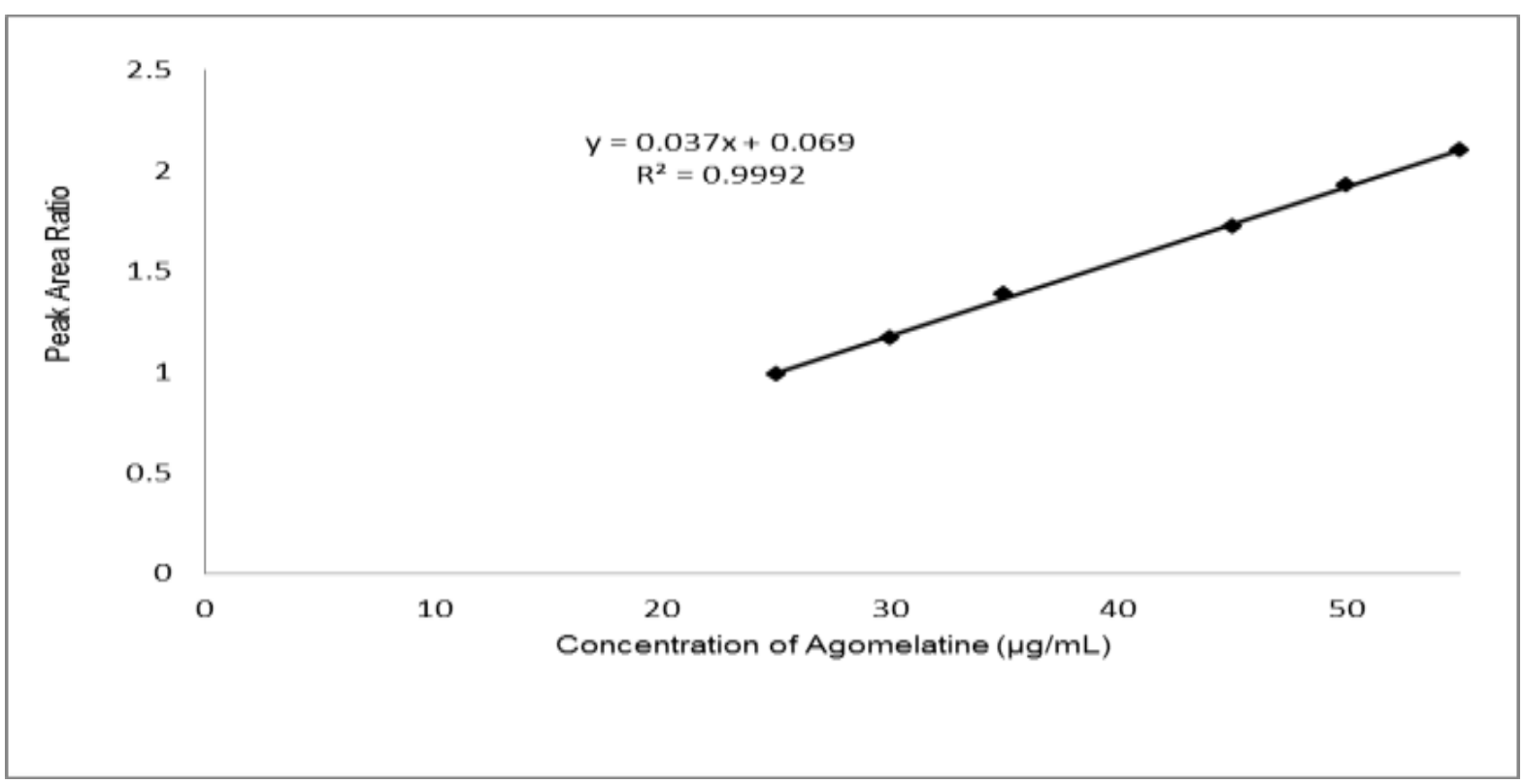

Figure 5: Linearity Curve of Agomelatine in Plasma 


\subsubsection{ACCURACY}

Accuracy was calculated as the percentage recovery of the known added amount of agomelatine reference substance in the sample solutions using three concentration levels covering the specified range $\left(12.5,25,37.5 \mu \mathrm{g} \mathrm{mL}{ }^{-1}\right.$ for tablets and $25,35,45 \mu \mathrm{g} \mathrm{mL}^{-1}$ for plasma). The accuracy of the method ranged from 100.5 to $100.9 \%$ for tablets, and from 97.84 to $101.24 \%$ for plasma indicating that this assay is reliable and accurate as the average recovery $\%$ is within the acceptance limit (Tables $2 \& 3$ ).

Table 2: Accuracy of Agomelatine by HPLC Method

\begin{tabular}{|c|c|c|c|c|c|}
\hline $\begin{array}{l}\text { Sample } \\
\text { No }\end{array}$ & $\begin{array}{c}\text { Conc. } \\
(\mu \mathrm{g} / \mathrm{ml})\end{array}$ & Response & $\begin{array}{l}\text { Average } \\
\text { Response }\end{array}$ & $\begin{array}{c}\text { Measured conc. } \\
(\mu \mathrm{g} / \mathrm{ml})\end{array}$ & $\begin{array}{c}\% \\
\text { Recovery }\end{array}$ \\
\hline \multirow{3}{*}{1} & \multirow{3}{*}{12.5} & 2014895 & \multirow{3}{*}{2207146.7} & \multirow{3}{*}{12.6} & \multirow{3}{*}{100.9} \\
\hline & & 2269640 & & & \\
\hline & & 2271125 & & & \\
\hline \multirow{3}{*}{2} & \multirow{3}{*}{25} & 4345575 & \multirow{3}{*}{4363338} & \multirow{3}{*}{25.1} & \multirow{3}{*}{100.7} \\
\hline & & 4322923 & & & \\
\hline & & 4421516 & & & \\
\hline \multirow{3}{*}{3} & \multirow{3}{*}{37.5} & 6687768 & \multirow{3}{*}{6531341.3} & \multirow{3}{*}{37.7} & \multirow{3}{*}{100.5} \\
\hline & & 6666870 & & & \\
\hline & & 6239386 & & & \\
\hline Average & & & & & 100.70 \\
\hline SD & & & & & 0.20 \\
\hline RSD\% & & & & & 0.199 \\
\hline
\end{tabular}

Table 3: Accuracy of Agomelatine by HPLC Method in Plasma

\begin{tabular}{|c|c|c|c|c|c|c|c|}
\hline \multirow{2}{*}{$\begin{array}{c}\text { Sample } \\
\text { No }\end{array}$} & \multirow[b]{2}{*}{$\begin{array}{l}\text { Conc. } \\
(\mu \mathrm{g} / \mathrm{ml})\end{array}$} & \multicolumn{2}{|c|}{ Agomelatine } & \multicolumn{2}{|c|}{ Fenoprofen (IS) } & \multirow{2}{*}{$\begin{array}{c}\text { Measured } \\
\text { conc. } \\
(\mu \mathrm{g} / \mathrm{ml}) \\
\end{array}$} & \multirow{2}{*}{$\begin{array}{c}\% \\
\text { Recovery }\end{array}$} \\
\hline & & Response & $\begin{array}{l}\text { Average } \\
\text { Response }\end{array}$ & Response & $\begin{array}{c}\text { Average } \\
\text { Response }\end{array}$ & & \\
\hline \multirow{3}{*}{1} & \multirow{3}{*}{25} & 1611029 & \multirow{3}{*}{1642939} & 1536238 & \multirow{3}{*}{1536028} & \multirow{3}{*}{24.46} & \multirow{3}{*}{97.84} \\
\hline & & 1673425 & & 1555055 & & & \\
\hline & & 1644363 & & 1516793 & & & \\
\hline \multirow{3}{*}{2} & \multirow{3}{*}{35} & 2180623 & \multirow{3}{*}{2080785} & 1546190 & \multirow{3}{*}{1564458} & \multirow{3}{*}{34.57} & \multirow{3}{*}{98.77} \\
\hline & & 2016070 & & 1561296 & & & \\
\hline & & 2045663 & & 1585890 & & & \\
\hline \multirow{3}{*}{3} & \multirow{3}{*}{45} & 2730535 & \multirow{3}{*}{2727071} & 1599415 & \multirow{3}{*}{1582338} & \multirow{3}{*}{45.56} & \multirow{3}{*}{101.24} \\
\hline & & 2748724 & & 1584729 & & & \\
\hline & & 2701956 & & 1562872 & & & \\
\hline Average & \multicolumn{7}{|c|}{99.28} \\
\hline SD & \multicolumn{7}{|c|}{1.75} \\
\hline RSD \% & \multicolumn{7}{|c|}{1.76} \\
\hline
\end{tabular}


To prove the accuracy of the proposed method, the results of the assay of the studied drug in pure form as well as in plasma and tablet formulation were compared with the results of reference method (Patil, et al., 2012). The statistical analysis (Miller JN, and Miller JC, 2005) of the results using student's t-test and variance ratio F-test showed no significant differences between them(Tables $4 \& 5$ ).

Table 4: Assay Results for the Determination of Agomelatine in pure form by the proposed HPLC and Reference methods

\begin{tabular}{|c|c|c|}
\hline Parameter & Proposed Method & Reference Method $^{[11]}$ \\
\hline \multirow{5}{*}{$\%$ Recovery $^{a}$} & 101.00 & 99.22 \\
\hline & 99.80 & 100.99 \\
\hline & 100.05 & 99.15 \\
\hline & 99.78 & 100.22 \\
\hline & 99.44 & 100.23 \\
\hline Mean \pm S.D & $100.01 \pm 0.59$ & $99.87 \pm 0.76$ \\
\hline $\mathbf{t}$ & \multicolumn{2}{|c|}{$0.33(2.78)^{\mathrm{b}}$} \\
\hline $\mathbf{F}$ & \multicolumn{2}{|c|}{$0.60(6.39)^{b}$} \\
\hline
\end{tabular}

a The average of three separate determinations.

$\mathrm{b}$ The figures between parentheses are the tabulated values of $\mathrm{t}$ and $\mathrm{F}$ at $\mathrm{P}=0.05$

Table 5: Assay Results for the Determination of Agomelatinein Tablet formulation and Plasma by the proposed HPLC and Reference Methods

\begin{tabular}{|c|c|c|}
\hline Sample & \multicolumn{2}{|c|}{ \% Recovery ${ }^{\mathbf{a}}$} \\
\hline \multirow{4}{*}{$\begin{array}{l}\text { Inspago } \\
\text { 25mg Tablets }\end{array}$} & Proposed Method & Reference Method $^{[11]}$ \\
\hline & 100.1 & 100.2 \\
\hline & 100.4 & 99.8 \\
\hline & 99.7 & 99.9 \\
\hline Mean \pm SD & $100.07 \pm 0.35$ & $99.97 \pm 0.21$ \\
\hline t & \multicolumn{2}{|c|}{$0.123(2.78)^{\mathrm{b}}$} \\
\hline $\mathbf{F}$ & \multicolumn{2}{|c|}{$2.78(19.0)^{b}$} \\
\hline \multirow{3}{*}{ Plasma } & 99.9 & 100.1 \\
\hline & 100.5 & 99.9 \\
\hline & 99.8 & 100.3 \\
\hline Mean \pm SD & $100.07 \pm 0.34$ & $100.1 \pm 0.20$ \\
\hline t & \multicolumn{2}{|c|}{$0.135(2.78)^{\mathrm{b}}$} \\
\hline $\mathbf{F}$ & \multicolumn{2}{|c|}{$2.89(19.0)^{b}$} \\
\hline
\end{tabular}

a The average of three separate determinations.

$\mathrm{b}$ The figures between parentheses are the tabulated values of $\mathrm{t}$ and $\mathrm{F}$ at $\mathrm{P}=0.05$

\subsubsection{PRECISION}

The study of method repeatability was conducted by performing six different test preparations from the same batch of Inspago $25 \mathrm{mg}$ tablets. The results shown in Table 6, indicates that the method is repeatable as the RSD is less than $2 \%$. The intermediate precision of the method was also evaluated using intraday and inter-day studies. For intraday studies, the drug at three concentrations was injected in triplicate into the HPLC system and for inter- 
day studies the drug at three concentrations were injected in triplicate into the HPLC system for three days (Table 7).

Table 6: Repeatability of the developed Method

\begin{tabular}{|c|c|c|}
\hline Concentration & Sample & Responses \\
\hline \multirow{4}{*}{$\mathbf{2 5 . 0} \boldsymbol{\mu g} / \mathbf{m L}$} & Test solution No.1 & 3693775 \\
\cline { 2 - 3 } & Test solution No.2 & 3683654 \\
\cline { 2 - 3 } & Test solution No.3 & 3725262 \\
\cline { 2 - 3 } & Test solution No.4 & 3600737 \\
\cline { 2 - 3 } & Test solution No.5 & 3722953 \\
\cline { 2 - 3 } & Test solution No.6 & 3700393 \\
\hline Average & \multicolumn{2}{|c|}{$\mathbf{3 6 8 7 7 9 5 . 6 6 7}$} \\
\hline SD & $\mathbf{4 5 6 7 4 . 0 0 6 3 9}$ \\
\hline RSD & \multicolumn{2}{|c|}{$\mathbf{1 . 2 4 \%}$} \\
\hline
\end{tabular}

Table 7: Intra-day and Inter-day validation of Agomelatine

\begin{tabular}{|c|c|c|c|c|c|c|}
\hline \multicolumn{4}{|c|}{ Intra-day validation } & \multicolumn{3}{|c|}{ Inter-day validation } \\
\hline $\begin{array}{c}\text { Sample } \\
\text { No }\end{array}$ & $\begin{array}{c}\text { Concentration } \\
(\mu \mathrm{g} / \mathrm{ml})\end{array}$ & $\begin{array}{c}\text { measured } \\
\text { conc. } \\
(\mu \mathrm{g} / \mathrm{ml})\end{array}$ & $\begin{array}{c}\% \\
\text { Recovery }\end{array}$ & $\begin{array}{c}\text { Concentration } \\
(\mu \mathrm{g} / \mathrm{ml}\end{array}$ & $\begin{array}{c}\text { measure } \\
\text { d conc. } \\
(\mu \mathrm{g} / \mathrm{ml})\end{array}$ & $\begin{array}{c}\% \\
\text { Recover } \\
\mathbf{y}\end{array}$ \\
\hline 1 & 12.5 & 12.5 & 100.0 & 12.5 & 12.6 & 100.9 \\
\hline 2 & 25.0 & 24.9 & 99.6 & 25.0 & 25.2 & 100.8 \\
\hline 3 & 37.5 & 37.6 & 100.3 & 37.5 & 37.4 & 99.7 \\
\hline Average & \multicolumn{3}{|c|}{99.97} & \multicolumn{3}{|c|}{100.47} \\
\hline SD & \multicolumn{3}{|c|}{0.35} & \multicolumn{3}{|c|}{0.67} \\
\hline RSD & \multicolumn{3}{|c|}{$0.35 \%$} & \multicolumn{3}{|c|}{$0.66 \%$} \\
\hline
\end{tabular}

\subsubsection{ROBUSTNESS}

Robustness of the method is a measure of its capacity to remain unaffected by small but deliberate variations in method parameters and provides an indication of its reliability during normal usage. To determine the robustness of the developed method, typical variations in some analytical conditions were tested including change of $\mathrm{pH}$ and change of column while the other mobile phase components were held constant in chromatographic condition. The RSD was not more than $2 \%$ (Table 8). The results obtained showed that the method is reliable during normal usage and indicating excellent robustness of the proposed method. 
Table 8: Robustness of the developed Method

\begin{tabular}{|l|c|c|c|c|}
\hline \multirow{2}{*}{ Sample } & \multicolumn{4}{|c|}{ Response } \\
\cline { 2 - 5 } & \multicolumn{2}{|c|}{ pH Change Study } & Column Change Study \\
\cline { 2 - 5 } & pH 2.5 & pH 2.6 & $\begin{array}{c}\text { Column } \\
\text { No.1 }\end{array}$ & $\begin{array}{c}\text { Column } \\
\text { No.2 }\end{array}$ \\
\hline Injection 1 & 4008432 & 4036621 & 4008432 & 3887293 \\
\hline Injection 2 & 3910812 & 3929897 & 3910812 & 4001409 \\
\hline Injection 3 & 3918288 & 4092486 & 3918288 & 4059457 \\
\hline Average & \multicolumn{3}{|c|}{3982756} & 3964281.80 \\
\hline SD & \multicolumn{3}{|c|}{74468.12} & 68246.19 \\
\hline RSD & $1.87 \%$ & \multicolumn{2}{c|}{$1.72 \%$} \\
\hline
\end{tabular}

\subsubsection{LIMIT OF DETECTION AND LIMIT OF QUANTITATION:}

LOD was determined by establishing the minimum level at which the analyte can reliably be detected (signal-to-noise ratio is $3: 1$ ) while LOQ was determined by establishing the lowest concentration of analyte that can be determined with acceptable precision and accuracy (signal-to-noise ratio is 10:1). The limits of detection (LOD) and the limits of quantification (LOQ) were calculated according to ICH Q2 (ICH, 2005) using the following equations:

$\mathrm{LOD}=3.3 \mathrm{Sa} / \mathrm{b}, \mathrm{LOQ}=10 \mathrm{Sa} / \mathrm{b}$

Where $\mathrm{Sa}=$ The standard deviation of the intercept of regression line $\mathrm{b}=$ Slope of the calibration curve. The results were shown in Table 1 .

\subsubsection{SPECIFITY AND SELECTIVITY}

Specificity and selectivity are evaluated by standard solutions against the placebo (formula without active substance) then inject the formula to check the separation of active substances from the excipients (lactose, starch - maize, povidone, sodium starch glycollate, stearic acid, magnesium stearate, silica - colloidal anhydrous hypromellose, iron oxide yellow (CI77492), glycerol, macrogol 6000, titanium dioxide (CI77891), shellac, indigo carmine (CI73015) and propylene glycol).Specificity and selectivity was evaluated by preparation of three samples with the same procedure stated in the method description. The 1 st sample is placebo (formula without active substance). The 2nd sample is standard solution (active ingredient with solvent only). The 3rd sample is the formula as is with the same solvent. Then inject the three samples to check the separation of active substances from the excipients and the ability of the preparation procedures to give $100 \%$ extraction of the active ingredient . The method found to be specific and selective for agomelatine because no interference between 
the peak corresponding to the active ingredients and any other peak corresponding to any inactive ingredients, and the response of standard sample and formula sample are so closed what means that the preparation procedures give near to $100 \%$ extraction of the active ingredient (Table 9).

Table 9: Specificity and Selectivity of Agomelatine by HPLC Method

\begin{tabular}{|l|l|l|}
\hline \multicolumn{1}{|c|}{ Test Name } & \multicolumn{1}{|c|}{$\begin{array}{c}\text { Observed peak of } \\
\text { Agomelatine }\end{array}$} & \multicolumn{1}{c|}{ Interference } \\
\hline Standard & 3911688 & No interference \\
\hline Tablets & 3680723 & No interference \\
\hline Placebo & $\begin{array}{l}\text { No peak at the same } \\
\text { retention time }\end{array}$ & $\begin{array}{l}\text { No peak at the same } \\
\text { retention time }\end{array}$ \\
\hline
\end{tabular}

\subsubsection{STABILITY OF ANALYTICAL SOLUTION}

The stability of the standard and sample solutions were tested at regular intervals. The stability of solutions was determined by comparing results of the assay of freshly prepared standard solutions. The differences in area $\%$ values were within $2 \%$ up to 72 hours for both standard and sample. Agomelatine stability was studied during sample collection, storage and preparation. All stability investigations were conducted using freshly prepared stock solutions in the mobile phase, as well as in the plasma matrix. Stability experiments have extended throughout the analysis duration and until the last test sample was assayed (Tables 10\&11).

Table 10: Stability of Agomelatine in the mobile phase

\begin{tabular}{|c||c|c|c||}
\hline Sample No & at zero time & After 6.0 hour R.T & After 12.0 days at -70 C. \\
\hline \hline 1 & 20700000 & 20700000 & 20400000 \\
\hline \hline 2 & 20900000 & 20000000 & 20600000 \\
\hline \hline 3 & 20600000 & 20900000 & 20500000 \\
\hline \hline 5 & 21500000 & 20100000 & 20200000 \\
\hline \hline 6 & 21100000 & 20300000 & 20700000 \\
\hline \hline 7 & 20600000 & 20600000 & 20100000 \\
\hline \hline Mean & 20828571.43 & 20471428.57 & 211570.09 \\
\hline \hline SD & 372890.89 & 340168.03 & 1.04 \\
\hline \hline Stability \% & 1.79 & 1.66 & 98.01 \\
\hline \hline & & 98.29 & 20414285.71 \\
\hline \hline & & & \\
\hline \hline
\end{tabular}


Table 11: Stability of Agomelatine in Plasma

\begin{tabular}{|c||c||c||}
\hline Sample & at zero time & After 8 hrs at R.T. \\
\hline \hline 1 & 3771435 & 3865767 \\
\hline \hline 2 & 3790940 & 3802637 \\
\hline \hline 3 & 3810567 & 3869595 \\
\hline \hline 5 & 3766068 & 3803517 \\
\hline \hline 6 & 3806230 & 3850767 \\
\hline \hline Mean & 3740583 & 3826705.333 \\
\hline \hline SD & 3780970.500 & 41264.007 \\
\hline \hline RSD\% & 26674.132 & 1.078 \\
\hline \hline Sability\% & 0.705 & $101.21 \%$ \\
\hline
\end{tabular}

\subsection{CONCLUSION}

Forced degradation study on agomelatine in plasma and tablet formulation was carried out under the conditions of acid hydrolysis.Based on the information generated by forced degradation, a stability-indicating assay method was developed and validated. The method was found sufficiently linear, precise, accurate, sensitive and specific to the drug. Study of various robustness parameters revealed the method to be robust. The resolution of drug and degradation products remained unaffected by change in analytical instrument.

\section{REFERENCES}

Daniela Tardito, RaffaellaMolteni, Maurizio Popoli, Giorgio Racagni (2012): European Neuropsychopharmacology, Volume 22, Supplement 3, S482-S486.

Howland, R,H. (2006): J.PsychosocNursMent Health Serv., 44, 13-17.

Howland, R.H (2009): Neuropsychiatric Disease and Treatment, 5, 563-576.

http://www.ema.europa.eu/humandocs/Humans/EPAR/valdoxan/valdox an.htm.

International Conference on Harmonization (ICH, 2003) Guidelines, Q1A (R2), Stability testing of new drug substances and products.

International Conference on Harmonization (ICH, 2005) Guidelines, Q2 (R1), Validation of analytical procedures: test and methodology.

Kasper S. (2011): European Psychiatry, Volume 26, Supplement 1, 2011, 2179.

Miller JN, Miller JC (2005): Statistics and Chemometrics for Analytical Chemistry, 5th edition. Pearson Education Limited, Harlow.

Patil, S. R., Nerurkar, K. K., Kalamkar, A. M., Pukale, V., Mangaonkar, K. V. and Pingale, S. G.(2012): Journal of Mass Spectrometry, Volume 47, 23-28. 
Peres, M.F., Masruha, M.R., Zukerman, E., Moreira-Filho, C.A., Cavalheiro, E.A (2006): Expert OpinInvestig Drugs 2006, 15, 367-375.

Srinivasan, V., Pandi-Perumal, S.R., Trakht, I., Spence, D.W.,Hardeland, R.,Poeggeler, B., Cardinali, D.P (2009): Psychiatry Res, 165,201-214.

Stein, D.J., Ahokas, A.A., de Bodinat, C., J (2008):Clin. Psychopharmacol, 28, 561-566.

The British Pharmacopoeia 2007. The Stationery Office, London; Electronic version.

The United States Pharmacopoeia 30, the National Formulary 25, (2007) US Pharmacopeial Convention; Electronic version.

Tinant, B. Declercq J.-P., Poupaert J. H., Yous S., Lesieur D. (1994): ActaCryst. C50 907910.

Wang Y., Liu Y., Lan J., Han J.P.,. Tian Q.S (2012): Determination of relative correction factor of impurity in crude agomelatine, Drugs Clin. 4, 370-373.

Wang Y.J., Zhang G.Y., Wang D.C., Tao W.B., Ge W.L. (2012): Determination of agomelatine in tablets by HPLC, Chin. JMAP, 29, 652-655.

Zlotos, D.P. (2005): Arch Pharm Chem Life Sci. 2005, 338, 229-247.

Zou Q.G., Hu Z.Y., Wei P. (2011): Determination of related substances in agomelatine and its capsules, J. Nanjing Xiaozhuang Univ. 6, 45-49.

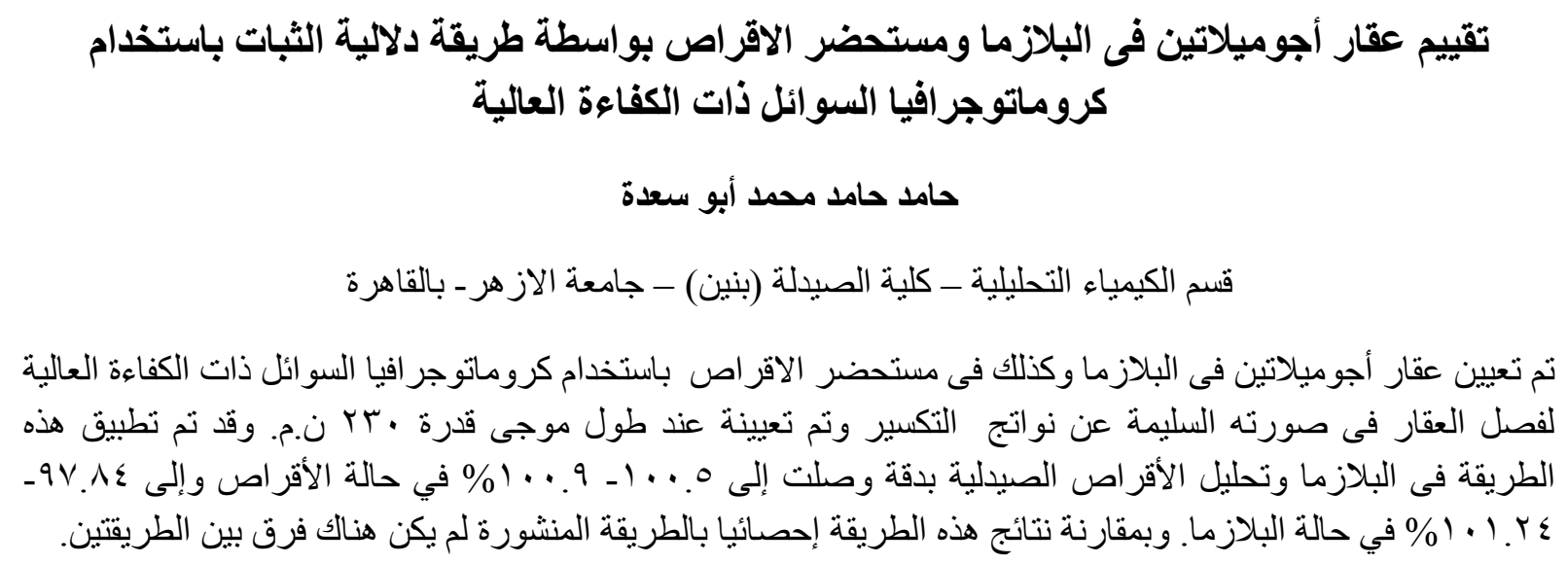

